\title{
Adaptations in anesthesiology residency programs amid the COVID-19 pandemic: virtual approaches to applicant recruitment
}

\author{
Donaldson C. Lee ${ }^{1 *}$, Alexander M. Kofskey ${ }^{1}$, Nikhi P. Singh ${ }^{1}$, Timothy W. King ${ }^{1}$ and Paul D. Piennette ${ }^{1,2}$
}

\begin{abstract}
Background: The COVID-19 pandemic significantly impacted residency recruitment in 2020, posing unique challenges for programs and applicants alike. Anesthesiology programs have adopted alternate methods of recruitment, including virtual open houses and social media, due to limiting personal contact rules implemented by AAMC. This study was undertaken to determine the frequency of virtual events hosted and social media accounts created by programs.

Methods: Anesthesiology residency programs and departments were examined for social media presence on Twitter, Instagram, and Facebook. Programs' websites and social media posts were reviewed for virtual open house opportunities. Available sub-internships were collected from the Visiting Student Application Service database. Data was collected after 2020-2021 pre-interview recruitment in October 2020.

Results: Of 153 total anesthesiology residency programs, 96 (63\%) had some form of social media presence. The platforms of choice for programs with social media accounts included Twitter (71, or 46\%), Instagram (67, or 44\%), and Facebook (47, or 31\%). Forty of seventy-six residency-affiliated accounts were created after March 1, 2020; Instagram accounts (26 of 40 ) represented most of these. Most Anesthesiology programs (59\%) offered virtual open houses for prospective applicants. Twitter (25\%), Instagram (22\%), and Facebook (8\%) were used by programs to advertise these events.

Conclusions: Social media presence of anesthesiology residency programs has grown steadily over the past decade, with exponential growth experienced in 2020. This data suggests that anesthesiology residency programs are employing new, mostly virtual, methods to reach prospective applicants during an unprecedented application cycle amidst the COVID-19 pandemic.
\end{abstract}

Keywords: Residency, Application, Virtual, COVID, Social media, Open house, Recruitment

\footnotetext{
*Correspondence: leeca@uab.edu

${ }^{1}$ School of Medicine, University of Alabama at Birmingham, Birmingham, AL 35233, USA

Full list of author information is available at the end of the article
}

(c) The Author(s). 2021 Open Access This article is licensed under a Creative Commons Attribution 4.0 International License, which permits use, sharing, adaptation, distribution and reproduction in any medium or format, as long as you give appropriate credit to the original author(s) and the source, provide a link to the Creative Commons licence, and indicate if changes were made. The images or other third party material in this article are included in the article's Creative Commons licence, unless indicated otherwise in a credit line to the material. If material is not included in the article's Creative Commons licence and your intended use is not permitted by statutory regulation or exceeds the permitted use, you will need to obtain permission directly from the copyright holder. To view a copy of this licence, visit http://creativecommons.org/licenses/by/4.0/ The Creative Commons Public Domain Dedication waiver (http://creativecommons.org/publicdomain/zero/1.0/) applies to the data made available in this article, unless otherwise stated in a credit line to the data. 


\section{Background}

The COVID-19 pandemic significantly impacted the 2020-2021 resident recruitment process [1]. Historically, visiting away rotations, or sub-internships (sub-I's), have played a role to assist residents' matching into highly competitive specialties, often at applicants' preferred institutions. In an Association of American Medical Colleges (AAMC) survey of 2019 medical school graduates, $42.8 \%$ of prospective anesthesia residents completed an away rotation [2]. Since the onset of the COVID-19 pandemic in the United States in early 2020, nearly all residency programs have suspended visiting away rotations and in-person interviews, following guidance from AAMC [3]. The American Society of Anesthesiologists (ASA) similarly recognized the unique difficulties that COVID-19 has placed on current residency applicants, emphasizing the need for increased virtual opportunities [4]. Without these unique experiences, students may lose valuable insight into programs where they may be interested in matching. Similarly constrained, programs may not be able to adequately assess and restrict their potential applicant pool.

Social media platforms present a mutually beneficial opportunity for residency programs to share information with prospective residents and for potential residents to evaluate residency programs. A previous survey across three anesthesia programs demonstrated that $52.8 \%$ of incoming residents considered information viewed on a prospective program's social media accounts to impact their rank list [5]. We assessed how anesthesiology programs have employed virtual opportunities, i.e., open houses ${ }^{1}$ and sub-internships, ${ }^{2}$ and social media to showcase their program attributes and interact with prospective residents in the unprecedented 2020-2021 application cycle.

\section{Methods}

After receiving exempt status from the UAB Institutional Review Board for Human Use, a list of all accredited anesthesiology programs was obtained from The Electronic Residency Application Service (ERAS); 153 total programs were identified. Through internet searches and investigation of each program's website, it was determined that programs' social media presence was exclusive to Twitter, Instagram, and Facebook. Each social media platform was examined to determine the

\footnotetext{
${ }^{1}$ Open Houses are informational sessions about residency programs, involving live presentations and/or informal meet-and-greets between applicants and various residency program representatives, including residents, faculty, and staff.

${ }^{2}$ Sub-internships (sub-is), also known as "away rotations" or "auditions," are clinical rotations of fourth-year medical students which are offered by programs affiliated separately from their home institutions. These are typically in students' specialty of interest and often utilized to demonstrate their commitment to the outside program.
}

existence of department and residency-affiliated program accounts. Residency-affiliated accounts included those run by administrative personnel, faculty, or residents and were labeled as such on their profiles; department accounts were considered as all other institution-specific anesthesiology accounts without an explicit description of being affiliated with a residency program. Accounts were reviewed for their listed creation date (or date of first post), virtual open house, and virtual sub-internship offerings. Accounts were determined to be officially associated with various anesthesiology department and residency programs by qualitative observation of the content and linkage to official residency and department websites. Open house opportunities were recorded by how many independent (non-ASA or AAMC associated), program-specific events were listed on each platform. Careful observation was performed to ensure that individual events were counted once, despite many being advertised with multiple successive posts. Program websites and an ASA-sponsored database $[6,7]$ were also investigated for virtual open house and virtual subinternship opportunities. The AAMC Visiting Student Application Service (VSAS) was reviewed to identify virtual sub-internship opportunities. Data was collected from October 15, 2020, to October 31, 2020, as this time frame followed the pre-interview recruitment season, i.e., when most open houses would have already been held, and roughly coincided with the date (October 21, 2020) when programs could begin viewing applications [8].

\section{Results}

Social media existence among accredited residency programs during the 2020-2021 application cycle is described in Table 1. Of the 153 anesthesiology residency programs, 96 (63\%) had some form of social media presence, by way of department and/or residency-affiliated account(s) on Twitter, Instagram, or Facebook. The platforms of choice for programs with social media accounts included Twitter (71, or 46\%) and Instagram (67, or $44 \%$ ), followed by Facebook (47, or 31\%). Twenty-four (16\%) programs appeared on all 3 platforms.

In total, 197 social media accounts existed across all anesthesiology programs. Annual account creation steadily increased from 7 in 2009 to 30 in 2019; this growth further increased to 54 accounts in 2020 (Fig. 1). Of the 76 residency-affiliated accounts across all platforms, 40 were created after March 1, 2020 (COVID-19 onset in the United States), and 14 of the 121 department accounts were formed in this timeframe (Fig. 2). Additionally, Instagram accounts topped all new account creations for anesthesiology residency accounts (26 out of 40) after the COVID-19 pandemic onset. Department accounts generated during this time were mostly on Twitter and Instagram (both 6 out of 14). 
Table 1 Virtual Characteristics of Anesthesiology Residency Programs, 2020-2021

\begin{tabular}{|c|c|}
\hline Virtual Opportunities and Social Media Platforms & n (\%) \\
\hline Total Anesthesiology Residency Programs & $\begin{array}{l}153 \\
(100)\end{array}$ \\
\hline Programs with $\geq 1$ Social Media Account(s) & $96(63)$ \\
\hline Programs on Twitter, Instagram, and Facebook ${ }^{a}$ & $24(16)$ \\
\hline \multicolumn{2}{|l|}{ Virtual Open Houses } \\
\hline - Programs with Advertised Virtual Open Houses & $91(59)$ \\
\hline - Programs with Virtual Open Houses on Program Website & $20(13)$ \\
\hline - Programs with Virtual Open Houses on ASA Link & $82(54)$ \\
\hline - Programs with Virtual Sub-Internships on VSAS & $2(1)$ \\
\hline - Programs with > 1 Advertised Virtual Open House & $37(24)$ \\
\hline \multicolumn{2}{|l|}{ Twitter } \\
\hline - Programs on Twitter ${ }^{a}$ & $71(46)$ \\
\hline - Programs with a Department Twitter & $61(40)$ \\
\hline - Programs with a Residency-Affiliated Twitter & $19(12)$ \\
\hline - Programs with Open House Opportunities on Twitter & $38(25)$ \\
\hline - Programs with > 1 Open House Opportunity on Twitter & $21(14)$ \\
\hline \multicolumn{2}{|l|}{ Instagram } \\
\hline - Programs on Instagrama & $67(44)$ \\
\hline - Programs with a Department Instagram & $22(14)$ \\
\hline - Programs with a Residency-Affiliated Instagram & $47(31)$ \\
\hline - Programs with Open House Opportunities on Instagram & $33(22)$ \\
\hline $\begin{array}{l}\text { - Programs with > } 1 \text { Open House Opportunity on } \\
\text { Instagram }\end{array}$ & $16(10)$ \\
\hline \multicolumn{2}{|l|}{ Facebook } \\
\hline - Programs on Facebook ${ }^{a}$ & $47(31)$ \\
\hline - Programs with a Department Facebook & $38(25)$ \\
\hline - Programs with a Residency-Affiliated Facebook & $10(6)$ \\
\hline - Programs with Open House Opportunities on Facebook & $13(8)$ \\
\hline $\begin{array}{l}\text { - Programs with }>1 \text { Open House Opportunity on } \\
\text { Facebook }\end{array}$ & $6(4)$ \\
\hline
\end{tabular}

aPrograms with department and/or residency-affiliated account(s)

Most anesthesiology residency programs (59\%) advertised virtual open houses across social media and program and ASA-sponsored websites for prospective applicants. Moreover, Twitter (25\%), Instagram (22\%), and Facebook (8\%) were used by programs to advertise these opportunities. More specifically, 37 (24\%) programs offered multiple events across all online platforms. Furthermore, virtual open houses were listed on 20 (13\%) programs' department or residency websites. A link on the ASA website with an editable document listed 82 programs with virtual open house opportunities. Two sub-internships were offered in a virtual format on the VSAS database. No programs offered virtual sub-internship opportunities on their websites or social media platforms.

\section{Discussion}

Anesthesiology residency programs have increasingly utilized social media in their efforts to recruit applicants over the past few years. The COVID-19 pandemic appears to have accelerated programs' use of social media. Annual account growth has more than quadrupled in the past 5 years and nearly doubled since the pandemic onset in March 2020. Despite the increasing importance of social media in announcing virtual opportunities, fewer than half of programs have employed multiple social media platforms to reach prospective applicants. Nevertheless, Instagram and Twitter appear to be the preferred platforms for outreach.

Although expanding their social media presence demonstrates progress in virtual engagement with applicants, programs may benefit from hosting forums, e.g., open houses, where applicants can engage in live conversation with program personnel. This could enable applicants to make better informed decisions when selecting the prospective institutions they plan to apply, visit, interview and ultimately attend [9]. These opportunities are likely valuable for individuals without anesthesia residency programs at their home institutions, who would otherwise utilize away rotations to familiarize themselves with residency programs. Approximately half of all programs offered virtual open houses, with only one-fifth holding multiple events. Offering additional opportunities may seem daunting for residencies; however, these likely do not exclusively benefit applicants-it may also streamline programs' efforts by refining their applicant pool to individuals who are best suited for their program. Moreover, virtual events may enable programs to gauge personalities and interest among applicants ahead of their interview or application review. This holds greater significance in a time when programs are expected to receive more applications than usual due to the elimination of interview travel expenses [10].

Although virtual sub-internships could also serve as opportunities for more expansive outreach, the existence of only two such programs may be attributed to the value of hands-on experience in anesthesia education. Nevertheless, programs may continue to offer videoconferences in future application cycles, as they are costeffective, compliant with social distancing guidelines, and desired as an option by both applicants and residents alike [11]. If future application cycles preserve virtual elements, such as videoconferences and virtual open houses, it would be logical to assume that medical student applicants would take advantage of these opportunities. To do so would allow applicants access to program characteristics and other basic information that could make programs desirable for a trainee with minimal travel or time expense. While in person interviews afford applicants the opportunity to experience the area and 


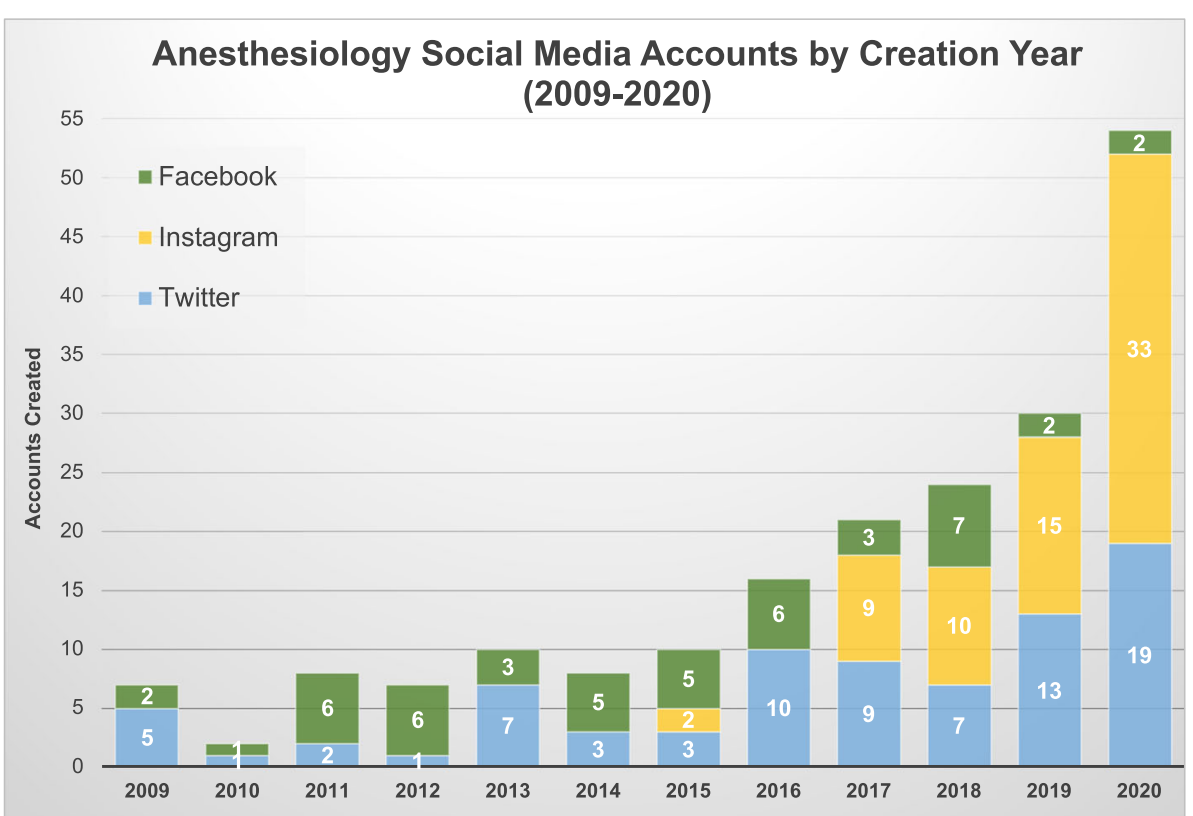

Fig. 1 Anesthesiology Social Media Accounts by Creation Year, 2009-2020

medical center firsthand, as well as connect in person with educators and current residents, this time and travel can be prohibitive, and virtual experiences can provide an alternative to or supplement traditional in person activities.

Moving forward, it will be crucial to understand the effect of social media and virtual events on anesthesiology residency programs during the 2020-
2021 application cycle. Individual programs would need to be surveyed on whether virtual tools enhanced their recruitment efforts, attracted new pools of applicants to their program, or transformed their approach to applicant outreach for upcoming interview seasons. Future investigation should explore how the landscape of anesthesiology residency applications has been altered by the emergence of virtual recruitment.

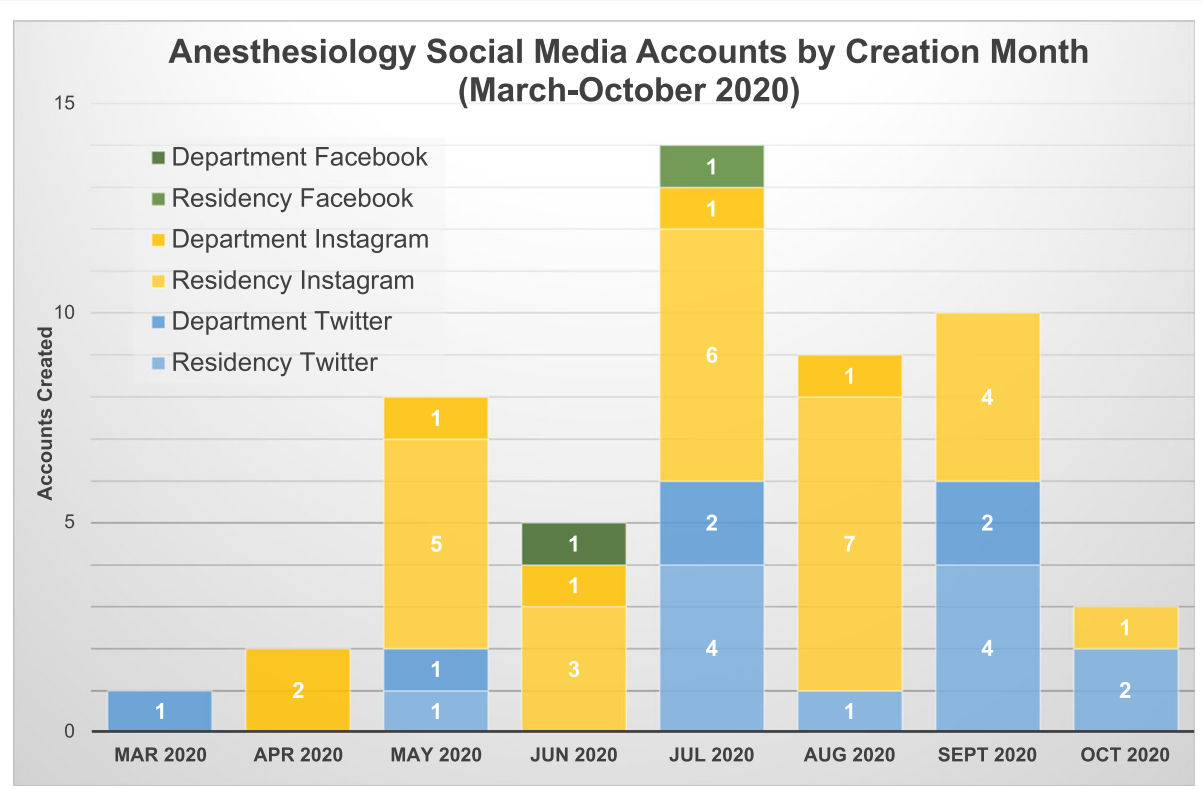

Fig. 2 Anesthesiology Social Media Accounts by Creation Month, March-October 2020 


\section{Conclusion}

The COVID-19 pandemic has posed unique challenges for the residency application process. In response, there has been exponential growth in social media accounts created by anesthesiology programs over the past year. Most programs have relied upon social media platforms to advertise virtual open houses and assist with anesthesiology resident recruitment.

\section{Acknowledgments}

Not applicable.

\section{Authors' contributions}

DL contributed as primary author by collecting data, performing data analysis, generating graphs, writing and revising the manuscript, and submitting the work to a journal. AK contributed by collecting data, performing data analysis, writing and revising the manuscript, and assisting with the journal submission process. NS contributed by organizing project methodology and revising the manuscript. TK contributed by formulating project idea and organizing project methodology. PP served as Senior Author by revising the manuscript and assisting with the journal submission process. All authors read and approved the final manuscript.

\section{Funding}

Not applicable.

\section{Availability of data and materials}

The datasets used and/or analyzed during the current study are available from the corresponding author on reasonable request.

\section{Declarations}

\section{Ethics approval and consent to participate}

This research does not report on or involve the use of any animal or human data or tissue. As such, this study was granted exemption status by the Institutional Review Board for Human Use at the University of Alabama at Birmingham, who also waived off the need for informed consent from participants. All methods were carried out in accordance with relevant guidelines and regulations.

\section{Consent for publication}

Not applicable.

\section{Competing interests}

The authors declare that they have no competing interests.

\section{Author details}

${ }^{1}$ School of Medicine, University of Alabama at Birmingham, Birmingham, AL 35233, USA. ${ }^{2}$ Department of Anesthesiology and Perioperative Medicine, University of Alabama at Birmingham, Birmingham, AL, USA.

Received: 22 March 2021 Accepted: 17 August 2021

Published online: 31 August 2021

\section{References}

1. Gabrielson AT, Kohn JR, Sparks HT, et al. Proposed changes to the 2021 residency application process in the wake of COVID-19. Acad Med. 2020; 95(9):1346-9.

2. Association of American Medical Colleges. Away rotations of U.S medical school graduates by intended specialty. In: 2019 AAMC medical school graduation questionnaire. 2019. https://aamc-orange.global.ssl.fastly.net/ production/media/filer_public/c6/a7/c6a79bc8-3279-4e0a-9bbf-7b9359172 db1/away_rotations_by_specialty_gq_2019_public.pdf. Accessed $17 \mathrm{Mar}$ 2021.

3. Association of American Medical Colleges. Medical student away rotations and in-person interview for 2020-21 residency cycle. 2020. https://www.aa mc.org/what-we-do/mission-areas/medical-education/away-rotationsinterviews-2020-21-residency-cycle. Accessed 9 Nov 2020.
4. American Society of Anesthesiologists. COVID-19 resources for medical students and residents. 2020. https:/www.asahq.org/education-and-career/a sa-medical-student-component/covid-19-resources-for-medical-students-a nd-residents. Accessed 9 Nov 2020.

5. Renew JR, Ladlie B, Gorlin A, Long T. The impact of social media on anesthesia resident recruitment. J Educ Perioper Med. 2019:21(1):E632.

6. American Society of Anesthesiologists. Residency information by state. 2020 . https://www.asahq.org/education-and-career/asa-resident-component/ residency-information-by-state. Accessed 9 Nov 2020.

7. American Society of Anesthesiologists. Anesthesiology virtual open houses for 2020 residency applicants. 2020. https://docs.google.com/spreadsheets/ d/1EZB7StsKLsuu8YK-Kb_s_EoYsmJMOQU6MObxk9Sml_0/edit\#gid=0. Accessed 9 Nov 2020.

8. Association of American Medical Colleges. Frequently asked questions for ERAS residency applicants. 2020. https://students-residents.aamc.org/a pplying-residency/faq/faq-eras-residency-applicants. Accessed 21 Mar 2021.

9. Jiang J, Key P, Deibert CM. Improving the residency program virtual open house experience: a survey of urology applicants. Urology. 2020;146:1-3.

10. Weiner S. Applying to residency is tough even in normal times. the pandemic isn't helping. In: AAMC news. Association of American Medical Colleges. https://www.aamc.org/news-insights/applying-residency-tougheven-normal-times-pandemic-isn-t-helping. Accessed 9 Nov 2020

11. Seifi A, Mirahmadizadeh A, Eslami V. Perception of medical students and residents about virtual interviews for residency applications in the United States. PLoS One. 2020;15(8):e0238239.

\section{Publisher's Note}

Springer Nature remains neutral with regard to jurisdictional claims in published maps and institutional affiliations.

\section{Ready to submit your research? Choose BMC and benefit from:}

- fast, convenient online submission

- thorough peer review by experienced researchers in your field

- rapid publication on acceptance

- support for research data, including large and complex data types

- gold Open Access which fosters wider collaboration and increased citations

- maximum visibility for your research: over $100 \mathrm{M}$ website views per year

At BMC, research is always in progress.

Learn more biomedcentral.com/submissions 